\title{
THE NORTH CAROLINA MEDICAID PROGRAM: PARTICIPATION AND PERCEPTIONS AMONG PRACTICING ORTHODONTISTS
}

\author{
Jannie Lee Im, DDS
}

A thesis submitted to the faculty of the University of North Carolina at Chapel Hill in partial fulfillment of the requirements for the degree of Master of Science in the School of Dentistry (Orthodontics).

\section{Chapel Hill}

2006

Approved by

Advisor: Ceib Phillips, PhD, MPH

Reader: Richard Beane, Jr., DDS

Reader: Jessica Lee, DDS, PhD, MPH 
(C)2006

Jannie Lee Im

ALL RIGHTS RESERVED 


\begin{abstract}
JANNIE LEE IM: The North Carolina Medicaid Program: Participation and Perceptions Among Practicing Orthodontists

(Under the direction of Dr. Ceib Phillips)
\end{abstract}

Limited provider participation in the Medicaid program is a barrier to access to orthodontic care for Medicaid-eligible patients. Questionnaires were mailed to all active orthodontists $(n=203)$ reported by the NC Health Professions Data System. Respondents were categorized as current Medicaid providers, past Medicaid providers, or orthodontists who have never accepted Medicaid. Of the 166 respondents, 24\% were current Medicaid providers, 20\% past providers, and 56\% never accepted Medicaid patients. Provider and practice characteristics of the three groups were similar. All three groups reported low fee reimbursement as a major problem. Those who have never participated in the Medicaid program were more likely to perceive program issues and patient behaviors as major problems than current or past providers. Past providers perceived broken appointments and tardiness to appointments as more of a problem than current providers. Perceptions of Medicaid patients and lack of knowledge appear to be major barriers to provider participation. 


\section{ACKNOWLEDGEMENTS}

I would like to sincerely thank my committee members, Dr. Ceib Phillips, Dr. Richard Beane, and Dr. Jessica Lee, for their input, guidance, and continual support throughout this project. As educators, they have made a significant contribution to my development intellectually and professionally.

I am also indebted to the following individuals for their contributions:

- Debbie Price, for her expeditious assistance with questionnaire formatting and data analysis.

- Dr. William Kalsbeek and the Survey Research Unit of the Biostatistics Department, for their assistance with questionnaire development.

- Teresa Edwards at the Odum Institute for Research in Social Science, for her assistance with questionnaire development.

- Daniel Im, my husband, for his unbelievable understanding, love, and support. 


\section{TABLE OF CONTENTS}

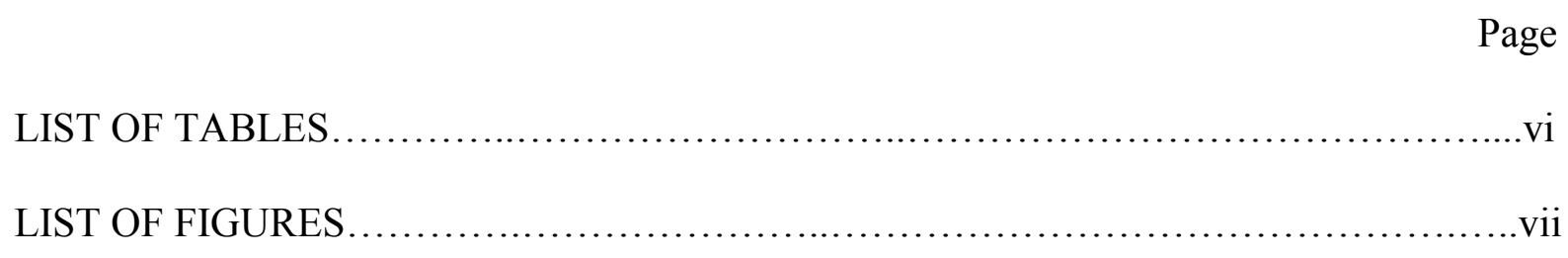

\section{SECTION}

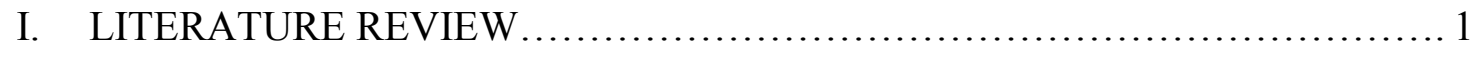

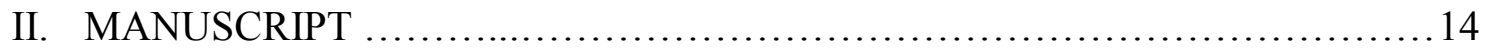

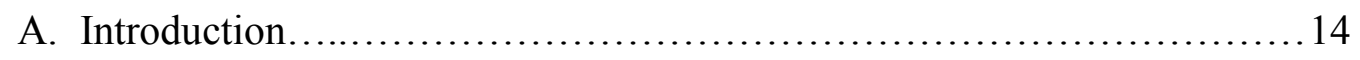

B. Material and Methods................................................ 16

C. Results............................................................. 18

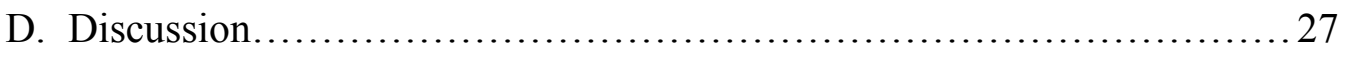

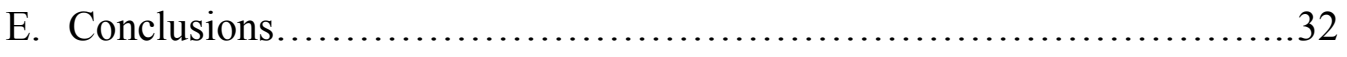

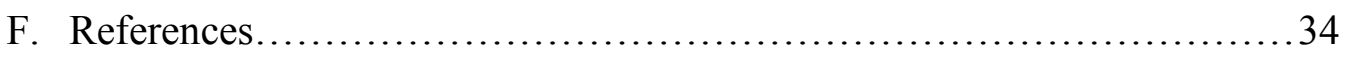




\section{LIST OF TABLES}

Table

1. Practitioner demographics...................................................... 20

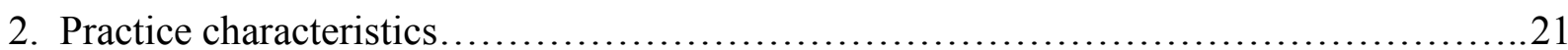

3. Number of current and past Medicaid providers by county........................... 23

4. Perceived problems with Medicaid................................................. 26 


\section{LIST OF FIGURES}

Figure

Page

1. County affiliations for respondents.............................................. 22 


\section{SECTION I}

\section{LITERATURE REVIEW}

Medicaid was established in 1965 as Title XIX of the Social Security Act to subsidize health care services for eligible individuals with low incomes and resources. The program finances health care coverage for about 40 million people, over half of whom are children. ${ }^{1}$ Within broad federal requirements, each state establishes its own eligibility standards; determines the type, amount, duration, and scope of services; sets the rate of payment for services; and administers its own program. ${ }^{2}$ Thus, Medicaid policies differ substantially from state to state.

In North Carolina, the Department of Health and Human Services (DHHS) administers the Medicaid program. According to DHHS, the annual number of people eligible for Medicaid increased from 456,000 in 1978 to $1,512,360$ in 2004 . The annual number of children eligible for Medicaid increased from 12,016 in 1987 to 522,133 in 2004. In 2004, 4166 dental providers, including general dentists, oral surgeons, pedodontists, and orthodontists, were enrolled in the NC Medicaid program. ${ }^{2}$ Medicaid programs will only fund orthodontic treatment for "functionally handicapping" conditions. The probability for approval by the N.C. Medicaid program is increased when two or more of the following criteria exist: severe skeletal condition; severe occlusal discrepancies or crossbites with functional shifts; functionally intolerable moderate to severe crowding; traumatic deep bite; an overjet of $6+\mathrm{mm}$; an openbite greater than 4 to $5 \mathrm{~mm}$; psychological and emotional 
factors; and potential that all problems will worsen. Orthodontic services are not covered in N.C. for the following types of cases: early treatment cases in the mixed dentition; interceptive orthodontics; minor tooth movement cases; canine impactions with a poor prognosis; posterior crossbites without a functional shift or history of temporomandibular dysfunction; Class I malocclusions with moderate crowding; mild to moderate anterior spacing; simple one arch treatment; localized tooth alignment problems; and cases begun prior to Medicaid eligibility. ${ }^{2}$

Despite the variation among states, the Early and Periodic Screening, Diagnostic, and Treatment (EPSDT) program, established by Congress in 1967, mandated that states provide comprehensive medical and dental services for all enrolled children, even if the services are not normally covered by a state's Medicaid program. ${ }^{1}$ This mandate included orthodontic treatment for a handicapping malocclusion. ${ }^{3-5}$ Barriers to care, however, have prevented the effective implementation of the EPSDT goals.

There are several different types of barriers to accessing oral health care, as outlined by Mertz et al. ${ }^{6}$ Four categories exist that can be applied from both the consumer perspective and the provider perspective: physical, financial, attitudinal, and process barriers. Physical barriers include those factors that prevent an individual from physically getting to available dental services (lack of available dentists in the area, a handicap, transportation issues, hours of operation for the dental office, wait time to schedule an appointment, etc.). Financial barriers are any cost or payment related issue that prevents an individual from seeking or obtaining care (lack of dental insurance, high cost of dental services, overhead costs for practices, administrative burdens, etc). Attitudinal barriers include the comfort level of the individual in the practice setting, his or her perceived oral health needs, emotional or 
circumstantial factors, and factors that influence how a provider views different segments of society. Finally, process barriers include lack of knowledge of eligibility for services, difficulty navigating the system or paperwork, the lack of evidence base for practice, and the ethical and moral issues in providing care.

Mertz et al. ${ }^{6}$ also discuss system barriers, which are different from the individual barriers discussed above. System barriers affect the whole community. These include education and workforce development issues, government funding and regulatory issues, private insurance industry issues, and other external issues.

Guay $^{7}$ believes that three essential interdependent elements must be addressed to adequately enhance access to care: the demand for dental care, the dental work force, and the economic environment. The demand for dental care, versus the need for dental care, includes factors that influence an individual's decision to seek dental care. Perceptions of need or lack of need for dental care may become a barrier in that it affects the willingness of the patient to seek care. There has to be an adequate work force to provide services to patients. Deficiencies can occur if there is an inadequate number of dentists or if there is a poor distribution of dentists within a state. Economic factors, such as low reimbursement fees and the ability for a patient to pay for care, must also be considered in outlining solutions to increasing access to care. ${ }^{7}$ Gold et al. ${ }^{8}$ argues that there are six classes of barriers to access: provider supply and distribution, program participation by providers, financial accessibility (coverage, benefits, and cost sharing), system accessibility (office hours, availability of appointments, transportation availability, rules regarding referrals to specialty services, etc.), patient knowledge, and system sensitivity to patient preferences. This review of the literature will concentrate on the dental work force/program participation by providers, attitudinal 
barriers, and the economic or financial (from the practitioner's perspective) elements of access to care.

The unwillingness of private practitioners to treat Medicaid patients has been a significant barrier to accessing health care since the implementation of the Medicaid program. Possible reasons for low practitioner participation include inadequate reimbursement, excessive paperwork and/or administrative burdens, payment delays, and patient abuses of the program. ${ }^{9,10}$ Mitchel1 ${ }^{11}$ compared physician participation rate information gathered in a 1977-78 national physician survey to data gathered from another national survey in 1984-85. She found a statistically significant decline in Medicaid participation rates. She also concluded that physicians treat significantly more Medicaid patients when the fee reimbursement level is relatively high and when there is a large number of eligible people in their area of practice. Margolis et al. ${ }^{12}$ also found that pediatricians in North Carolina who received a higher proportion of their customary fee were less likely to restrict access. However, this relationship was weakened after controlling for the size of the community, the pediatricians' attitudes, whether they felt they were too busy to see Medicaid patients, and whether they believed Medicaid patients had access to other resources of care. Gold et al. ${ }^{8}$ reviewed available research and found that more recent studies demonstrate that reimbursement level has smaller, mixed, or no effects on Medicaid participation. Thus, increasing practitioner participation may take more than just increasing fee reimbursement. Margolis et al. ${ }^{12}$ go on to state that there may be a stronger relationship between the size of the local community and the decision to restrict access. Commonly cited reasons for restricting access included the Medicaid bureaucracy, the characteristics of the Medicaid population, and the effect Medicaid would have on revenue. Busyness, the belief that there 
were other resources for Medicaid patients, and lack of knowledge about the Medicaid program also affected participation in Medicaid.

Low practitioner participation in the Medicaid program is also a problem in dentistry. Several studies have been conducted to determine factors that may influence the decision to provide care for Medicaid-eligible patients. Lang and Weintraub ${ }^{5}$ surveyed general dentists in Michigan and found that about half of the respondents did not accept Medicaid, 29\% had less than $10 \%$ of their patient population on Medicaid, and $22 \%$ had $10 \%$ or more Medicaideligible individuals in their patient population. They found that dentists who treated more Medicaid patients were younger, had been in practice fewer years, are more likely to be in group practices, and saw a higher number of new patients per month. Dentists in rural areas were also more likely to accept Medicaid patients. The following reasons were suggested to explain these differences: younger dentists may need to fill up more available appointment time, more new patients may be scheduled because of the likelihood of broken appointments, and geographic differences in participation may be related to economic differences in the areas. The authors also state possible reasons for the low participation level found among Michigan dentists: an inadequate fee schedule, dissatisfaction with prior authorization procedures and restrictions compared to private dental insurance, delays in receiving payments, and frequent broken appointments. These reasons are very similar to those given by physicians for restricting access.

Capilouto $^{13}$ discussed possible factors affecting dentists' decisions to treat Medicaid patients. Such factors include low reimbursement rates, restrictions on services, greater administrative burdens, broken appointments, poor compliance by patients, and the belief that patients place little value on dental care. He went on to state that some dentists may not 
participate in Medicaid because they believe they will be frowned upon by others due to an association with fraud and abuse. This association arises from the idea that the Medicaid system encourages participants to overtreat and/or provide poor quality care.

Damiano et al. ${ }^{14}$ conducted telephone interviews with 92 dentists (44 Medicaid participants and 48 nonparticipants) in California to determine factors affecting their decisions to participate in the Medicaid program. Dentists saw low fee reimbursement, administrative difficulties, and broken appointments as the three most important problems with the Medicaid program. Non-providers were more concerned with broken appointments and complicated paperwork, and were less likely to believe the complexity of the California Medicaid program had improved. Medicaid providers were more concerned with the lack of services covered by the program. The author stressed that communication between the Medicaid program and dentists is essential to increasing practitioner participation. Damiano et al. describe the administrative problems of Medicaid as the "hassle factor," which includes paperwork requiring different claim forms and procedure codes than private insurance companies, denial of payment, need for prior authorization, and lack of covered services. The idea of a "Medicaid mill," a term used to describe large volume, low quality Medicaid practices, is introduced as a possible result of a small number of practices treating a relatively high percentage of Medicaid patients. The author warned that if fees are not increased and the "hassle factors" reduced, an increasing number of dentists may discontinue accepting Medicaid patients in the future.

A survey study of pediatric dentists' participation in the North Carolina Medicaid program found that $75 \%$ of pediatric dentists placed some limit on access to their practices for Medicaid patients, with $57 \%$ believing that treating Medicaid patients resulted in a net 
loss of income. Twenty-five percent of all NC pediatric dentists accepted all Medicaid patients. This group was more likely to have a large proportion of Medicaid patients in their practices and was more likely to report a net profit from participating in the Medicaid program. Inadequate reimbursement was the most important reason given for limiting access. Fear of broken/canceled appointments was the second strongest reason to limit Medicaid participation, and the need for prior authorization was the third most important reason. Busyness was also an important factor in practitioner participation. Unlike the study done by Lang and Weintraub ${ }^{5}$, this study found that $\mathrm{NC}$ pediatric dentists who had been in practice longer were more likely to accept all new Medicaid patients. ${ }^{4}$

In January 1994, Medicaid fees in Connecticut were increased to $80 \%$ of the usual and customary rate. A survey conducted in December 1994 showed that the fee increase did affect access to dental care for Medicaid patients. The proportion of Medicaid providers who restricted the percentage of Medicaid children in their practice to less than $10 \%$ decreased from one-third to one-fourth, and the percentage of dentists accepting new Medicaid-eligible children increased from one-third to one-half. The number of pediatric dentists accepting new Medicaid children almost doubled, and the percentage of Medicaid children in their practices increased. ${ }^{15}$

Telephone interviews of dentists in Washington State revealed that the single most important factor influencing their decision to treat Medicaid children was the low fee reimbursement paid by Medicaid. General dentists who saw a higher number of Medicaid patients per week had more inquiries per week by Medicaid clients. Average fees were lower among practices in rural areas than in suburban areas. Unlike the findings of King et al. ${ }^{16}$ and Lang and Weintraub ${ }^{5}$, no difference was found in Medicaid participation levels by 
practice location. However, practices with higher fees tended to see fewer Medicaid-eligible children, supporting the theory put forth by Margolis et al. ${ }^{12}$ that practitioners who received a higher proportion of their usual and customary fees may be less likely to restrict access. The number of years in practice did not seem to matter, but older dentists were less likely to treat Medicaid children, which was similar to the findings of Lang and Weintraub ${ }^{5}$ but different from those of Venezie and Vann ${ }^{4}$. Unlike the findings of many studies, most Medicaid patient behaviors were considered to be minor problems for the majority of the dentists interviewed. ${ }^{17}$

Shulman et al. ${ }^{18}$ surveyed attitudes that Louisiana dentists had of the Medicaid program. They examined the following Medicaid-related issues: broken appointments, low fees, patient non-compliance, frequent denial of payments, requirement for prior approval, slow payment, frequently changing regulations, intermittent patient eligibility, complicated paperwork, and too few practices accept Medicaid-enrolled children. With the exception of broken appointments, non-participating dentists felt that the above issues were more important than enrolled dentists. Broken appointments, low fees, and patient noncompliance, in decreasing order, were considered the most important issues. In comparison to private dental insurance, both Medicaid providers and non-providers felt that the only significant difference was reimbursement levels. However, $24 \%$ of the nonparticipating dentists stated that they would consider participating in the Medicaid program if the reimbursement fees were raised to a level similar to the customary fees; $49 \%$ would participate only if other changes were also made in the program; and $27 \%$ stated that they would not participate under any circumstances. This result shows that increasing reimbursement levels alone will not substantially increase participation. In addition, their 
data showed that newly graduated dentists were more likely to be actively participating in the Medicaid program.

Little has been published regarding orthodontists' participation in the Medicaid program and their attitudes toward the Medicaid system and its clients. King et al. ${ }^{16}$ conducted a study to assess the likelihood that a publicly-funded early interceptive program would increase Medicaid participation by orthodontists, increasing access for low-income children. They surveyed 210 orthodontists in the state of Washington, with an effective response rate of $76 \%(159 / 208)$. Their survey had four general categories: practice demographics, attitudes toward early orthodontic treatment, acceptance of innovative orthodontic approaches, and perceptions of the Medicaid system. Orthodontists who treated at least one Medicaid patient during the previous year were categorized Medicaid participants. Fifty (31.4\%) respondents were Medicaid participants by this definition, with $6.1 \%$ of their patient population enrolled in Medicaid. They found no differences in average fees, practice arrangement, number of new cases started, or mean number of years in practice between participants and nonparticipants. Medicaid providers were more likely to be in rural areas, had fewer patients with private insurance, provided more discounted fees, received more inquiries from Medicaid patients, and were more likely to feel overworked. Both Medicaid participants and nonparticipants felt that there was some benefit to early orthodontic treatment, but Medicaid providers were more willing to participate in a Medicaid-sponsored program of interceptive orthodontic treatment. Medicaid participants reported fewer problems with Medicaid in only two of the ten issues given: "getting billing questions answered" and "need for prior authorization". Both Medicaid providers and nonproviders felt that low reimbursement was the largest problem. Both groups of 
respondents considered the following issues significant, in descending order of importance: "patient may fail to show up for appointments," "difficulty collecting from Medicaid," "delays in receiving payment," and "patients are often late." Both groups reported that "unruly or uncooperative patients," "loss of coverage during treatment," and "patients cancel at the last minute" were not as significant as other factors. King et al. concluded by stating that if a Medicaid-sponsored program of early orthodontic treatment is to succeed, educational initiatives to familiarize nonparticipants with Medicaid and the new program would be essential.

There have been several suggestions for improving practitioner participation in the Medicaid program. Shulman et al. ${ }^{18}$ suggested that fees should be increased but that raising reimbursement rates alone will not increase the level of participation. Further suggestions included streamlining and simplifying the claims process, assigning a case manager to a Medicaid-eligible family, and modifying rules to decrease the providers' financial risk/burden. Capilouto ${ }^{13}$ agrees that increasing reimbursement rates alone may not ensure increased access to dental care. Other factors, such as administrative inconveniences and uncooperative patients, need to be considered. Controversial options were introduced, such as linking licensure to agreements to accept Medicaid patients or giving more favorable income tax rates for those who treat more Medicaid-eligible individuals. Milgrom and Riedy ${ }^{17}$ suggest that some of the patient-related problems dentists report having can be solved by client education, by asking Medicaid patients to call and confirm their appointments beforehand, and ensure transportation arrangements have been made before confirming their appointments. They go on to state that requiring all licensed dentists to see their share of Medicaid clients is an option, but that it is not likely to be successful. State and 
local dental societies along with community leaders can possibly change practitioners' attitudes through professional education and ensuring that local practitioners are aware of the lack of access to care for the underprivileged. Fees can be increased, and administrative procedures can be streamlined. Specifically for the orthodontic field, King et al. ${ }^{16}$ recommended a new program that funds early orthodontic treatment, which could reduce the costs per patient due to decreased complexity, as a means to increase access. However, this alone may not increase the level of participation by orthodontists. 


\section{REFERENCES}

1. GAO (2000) Oral Health: Dental Disease is a Chronic Problem Among Low-Income Populations. Washington, DC: General Accounting Office, April 2000.

2. Medicaid in North Carolina Annual Report State Fiscal Year 2004. Raleigh, NC: North Carolina Department of Health and Human Services Division of Medical Assistance, June 2005.

3. Parker WS. Government and orthodontics in California in 1994. Am J Orthod Dentofacial Orthop. 1995 Mar;107(3):22A-3A.

4. Venezie RD, Vann WF,Jr. Pediatric dentists' participation in the North Carolina Medicaid program. Pediatr Dent. 1993 May-Jun;15(3):175-81.

5. Lang WP, Weintraub JA. Comparison of Medicaid and non-Medicaid dental providers. J Public Health Dent. 1986 Fall;46(4):207-11.

6. Mertz EA, Manuel-Barkin CE, Isman BA, O’Neil EH. Improving Oral Health Care Systems in California: A Report of the California Dental Access Project. San Francisco, CA: The Center for the Health Professions, University of California, San Francisco. December 2000.

7. Guay AH. Access to dental care: solving the problem for underserved populations. J Am Dent Assoc. 2004 Nov;135(11):1599,605; quiz 1623.

8. Gold M, Kuo S, Taylor EF. Translating research to action: improving physician access in public insurance. J Ambul Care Manage. 2006 Jan-Mar;29(1):36-50.

9. Silverstein G. Physicians' perceptions of commercial and Medicaid managed care plans: a comparison. J Health Polit Policy Law. 1997 Feb;22(1):5-21.

10. Garner DD, Liao WC, Sharpe TR. Factors affecting physician participation in a state Medicaid program. Med Care. 1979 Jan;17(1):43-58.

11. Mitchell JB. Physician participation in Medicaid revisited. Med Care. 1991 Jul;29(7):645-53.

12. Margolis PA, Cook RL, Earp JA, Lannon CM, Keyes LL, Klein JD. Factors associated with pediatricians' participation in Medicaid in North Carolina. JAMA. 1992 Apr 8;267(14):1942-6.

13. Capilouto E. The dentist's role in access to dental care by Medicaid recipients. J Dent Educ. 1988 Nov;52(11):647-52.

14. Damiano PC, Brown ER, Johnson JD, Scheetz JP. Factors affecting dentist participation in a state Medicaid program. J Dent Educ. 1990 Nov;54(11):638-43. 
15. Nainar SM, Tinanoff N. Effect of Medicaid reimbursement rates on children's access to dental care. Pediatr Dent. 1997 Jul-Aug;19(5):315-6.

16. King GJ, Hall CV, Milgrom P, Grembowski DE. Early orthodontic treatment as a means to increase access for children enrolled in medicaid in Washington state. J Am Dent Assoc. 2006 Jan;137(1):86-94.

17. Milgrom P, Riedy C. Survey of Medicaid child dental services in Washington state: preparation for a marketing program. J Am Dent Assoc. 1998 Jun;129(6):753-63.

18. Shulman JD, Ezemobi EO, Sutherland JN, Barsley R. Louisiana dentists' attitudes toward the dental Medicaid program. Pediatr Dent. 2001 Sep-Oct;23(5):395-400. 


\section{SECTION II}

\section{MANUSCRIPT}

In 1965, Medicaid was created as Title XIX of the Social Security Act to provide public health insurance to certain low-income individuals. ${ }^{1}$ In 1966, an American Dental Association task force specifically recommended that treatment services include "treatment of malocclusion with priority provided for interceptive service and disfiguring or handicapping malocclusions." ${ }^{2}$ An amendment passed in 1967 established the Early and Periodic Screening, Diagnosis, and Treatment (EPSDT) program, which mandated that dental care, including orthodontic treatment for handicapping malocclusion, be made available to Medicaid-eligible children less than 21 years of age. ${ }^{3-5}$ One significant obstacle in achieving the legislative mandate of the EPSDT legislation has been limited provider participation by dentists in the Medicaid program.

From the Medicaid recipient's perspective, difficulty finding a provider, limited number of available appointments, transportation problems, excessive wait times, and discriminatory behavior from staff and providers have been identified as problems in accessing dental care. ${ }^{6}$ Low participation by dentists in the Medicaid program has been linked to low reimbursement rates, excessive paperwork, need for prior authorization, denial of payment, restrictions in reimbursable services, payment delays, and broken appointments. $^{4,5,7-11}$ Capilouto $^{8}$ presented other possible dimensions for low provider participation related to peer and professional considerations such as the linkage of Medicaid 
providers with fraud and abuse in the media and the perception that Medicaid providers are held in lower esteem by peers.

From 2002 to 2003, an estimated 480,000 children in North Carolina were eligible for dental treatment under the Medicaid program. During the same time period, less than $0.5 \%$ of these children received any orthodontic care (N.C. DHHS 2004, unpublished data), even though it has been estimated that $29 \%$ of adolescents and $14.2 \%$ of children have a severe to very severe handicapping malocclusion. ${ }^{12,13}$ The low percentage of Medicaid-eligible children that received orthodontic care in N.C. in 2003 appears to reflect the level of care in other states. Less than $1 \%$ of eligible children in Washington state received orthodontic care in 1999 , with ten orthodontists providing approximately $81 \%$ of the orthodontic treatment statewide. ${ }^{14}$ The N.C. Department of Health and Human Services (DHHS) reported that ten orthodontists accounted for $83.6 \%$ of the total number of Medicaid cases banded in 20022003, emphasizing the poor distribution of these cases among practitioners.

Little has been published regarding orthodontists' participation in and attitudes toward Medicaid. A survey of orthodontists in Washington State indicated that providers in rural areas were more likely to treat Medicaid patients. Medicaid providers had slightly fewer patients with private insurance, provided more discounted fees, and received more inquiries from Medicaid patients. They were more likely to feel overworked, and reported fewer problems with the Medicaid system. Low fee reimbursement was the most important perceived problem by both Medicaid participants and non-participants. ${ }^{14}$ The goals of this investigation were to validate findings by King and colleagues, provide new insights on provider perceptions, and examine any regional differences in provider participation. Accordingly, the specific aims were 1) to determine the level of participation of $\mathrm{NC}$ 
orthodontists in the Medicaid program; 2) to examine NC orthodontists' perceptions of and attitudes toward the Medicaid program and its beneficiaries; and 3) to determine whether there are differences between NC practitioners who do and who do not accept Medicaid patients. A greater understanding of the barriers to participation by orthodontists will provide insight into what changes, whether in program policy or in orthodontists' attitudes, may be needed to improve access to orthodontic care for those who meet Medicaid criteria.

\section{MATERIALS AND METHODS}

A cross-sectional census study design was used to assess the level of participation of North Carolina orthodontists in the Medicaid program and perceptions they may have of the Medicaid system and its clients. The survey instrument was approved by the Institutional Review Board at the University of North Carolina School of Dentistry. The survey instrument completed by practicing orthodontists consisted of 28 items using Likert Scale type responses for most questions.

\section{Instrument development and testing}

Survey questions were derived from previously developed and tested survey instruments ${ }^{4,14}$ and new ones developed to meet specific research aims. The questionnaire was pre-tested on full-time orthodontic faculty at the University of North Carolina who were asked to provide open-ended comments regarding ease of completion, confusing items, and word changes. These individuals were excluded from the final study sample. The Survey Research Unit of the Biostatistics Department and the Assistant Director for Survey Research and Development at the Odum Institute for Research in Social Science at the University of North Carolina also reviewed and assisted with development of the final questionnaire. 
The survey instrument was divided into four domains: patient population, practitioner demographics (Table I), practice characteristics (Tables II and III), and Medicaid issues (Table IV). Practice arrangement was categorized as solo practitioner and non-solo practitioner for analytical purposes. Prior to questions regarding the respondent's perception of typical reasons why dentists limit the number of Medicaid patients they treat, respondents were asked if they currently accepted new Medicaid patients and, if yes, what percentage of the active patient population was Medicaid; whether all new Medicaid patients were accepted; and whether the amount of Medicaid revenue resulted in a net profit, breaking even, or a net loss. Those respondents who did not currently accept new Medicaid patients were asked if they had ever accepted Medicaid patients and, if so, in what year they stopped accepting Medicaid patients. Finally, ten commonly cited problems with the Medicaid program and patients that have been identified as barriers to participation were given (Table IV). The respondents were asked if they perceived each of these problems to be "not a problem", "a minor problem", "a major problem", or "don’t know".

\section{Data collection}

We obtained practitioner data information from the North Carolina Health Professions Data System (HPDS), which is maintained by the Policy Unit within the Cecil G. Sheps Center for Health Services Research in collaboration with the North Carolina Area Health Education Centers Program (AHEC) of the University of North Carolina at Chapel Hill and the independent health professions licensing boards in the State. The survey was mailed to all active orthodontists practicing in North Carolina as reported in the North Carolina State Dental Board of Licensing Section of the HPDS. The sampling frame identified two hundred and fifteen orthodontists, but twelve of the orthodontists were not eligible: one was deceased 
and eleven were not active practitioners. Thus, the effective sampling frame was 203 . The survey methods outlined in Salant and Dillman ${ }^{15}$ were used as a guide. A cover letter describing the study, the questionnaire, and a postage-paid return envelope was sent to each orthodontist. A follow-up letter, along with a replacement questionnaire, was mailed approximately 2 to 3 weeks later to the orthodontists who had not responded. A third contact letter, along with another copy of the questionnaire, was sent to non-respondents 2 to 3 weeks after the second letter. Data collection occurred between August and November 2005. Analysis

Respondents were categorized as: 1) current Medicaid providers, 2) providers who had participated in Medicaid at one time but did not currently participate, and 3) providers who had never participated in Medicaid. Univariate descriptive statistics were calculated for each question. The responses of the three groups of Medicaid providers (current, past, and never) to all items were compared using the exact Mantel-Haenszel Chi-square test except for those questions with continuous responses, eg. percent of patients with insurance. For these items, the Mantel-Haenszel row-mean score statistic was used to compare the three groups. Respondents who specified "Don't Know" to the barrier to participation items were excluded to yield a comparison of providers in the three groups who expressed an opinion. The number of respondents differed from question to question since some respondents did not answer every question. The level of significance was set at 0.05 for all analyses.

\section{RESULTS}

One hundred sixty eight eligible orthodontists responded to the survey. Two respondents were excluded from the data analysis because they responded with letters rather than completing the questionnaire, yielding an effective response rate of $166 / 203(82 \%)$. The 
average age of the respondents was 51 years old ( $\mathrm{SD} \pm 10.8)$, with a range of 32 to 81 . The majority of the respondents were male $(86.8 \%)$, Caucasian $(94.5 \%)$, solo practitioners (73.3\%), and had been in practice for an average of 19.5 years $(\mathrm{SD} \pm 10.2)$ (Table I). Nearly $95 \%$ reported working at least three or more days a week. Tables I and II summarize the practitioner and practice characteristics of the respondents. 


\begin{tabular}{|c|c|c|c|c|c|c|c|c|c|}
\hline \multicolumn{10}{|c|}{ TABLE I: PRACTITIONER DEMOGRAPHICS } \\
\hline & \multicolumn{2}{|r|}{ Total } & \multicolumn{2}{|c|}{ Medicaid Providers } & \multicolumn{2}{|c|}{$\begin{array}{l}\text { Accepted Medicaid at } \\
\text { one time }\end{array}$} & \multicolumn{2}{|c|}{$\begin{array}{l}\text { Never Accepted } \\
\text { Medicaid }\end{array}$} & \multirow[t]{2}{*}{ p value } \\
\hline & $\mathbf{N}$ & Median (q1 -q3) & $\mathbf{N}$ & Median (q1 -q3) & $\mathbf{N}$ & Median (q1 -q3) & $\mathbf{N}$ & Median (q1 -q3) & \\
\hline Age (years) & 161 & $51(43-59)$ & 39 & $49(43-59)$ & 33 & $53(46-60)$ & 89 & $51(41-59)$ & 0.65 \\
\hline $\begin{array}{l}\text { Number of years in } \\
\text { practice }\end{array}$ & 164 & $20(10.5-29)$ & 39 & $19(12-30)$ & 33 & $20(11-29)$ & 92 & $20.5(10-27.5)$ & 0.93 \\
\hline \\
\hline & & N \% & & N \% & & N \% & & N \% & \\
\hline $\begin{array}{cc}\text { Gender } & \begin{array}{c}\text { Female } \\
\text { Male }\end{array} \\
\end{array}$ & & $\begin{array}{l}22(13.25) \\
144(86.75)\end{array}$ & & $\begin{array}{c}7(17.50) \\
33(82.50)\end{array}$ & & $\begin{array}{c}3(9.09) \\
30(90.91)\end{array}$ & & $\begin{array}{l}12(12.90) \\
81(87.10)\end{array}$ & 0.59 \\
\hline Race & & & & & & & & & \\
\hline Caucasian & & $154(94.48)$ & & $35(89.74)$ & & $29(90.63)$ & & $90(97.83)$ & 10 \\
\hline African-American & & $5(3.07)$ & & $2(5.13)$ & & $3(9.38)$ & & $0(0)$ & 1.0 \\
\hline Other & & $4(2.45)$ & & $2(5.13)$ & & $0(0)$ & & $2(2.17)$ & \\
\hline
\end{tabular}




\begin{tabular}{|c|c|c|c|c|c|c|c|c|c|}
\hline \multicolumn{10}{|c|}{ TABLE II: PRACTICE CHARACTERISTICS } \\
\hline & \multicolumn{2}{|r|}{ Total } & \multicolumn{2}{|c|}{ Medicaid Providers } & \multicolumn{2}{|c|}{$\begin{array}{c}\text { Accepted Medicaid at } \\
\text { One Time }\end{array}$} & \multicolumn{2}{|c|}{$\begin{array}{l}\text { Never Accepted } \\
\text { Medicaid }\end{array}$} & \multirow{2}{*}{$\begin{array}{c}P \\
\text { value }\end{array}$} \\
\hline & $\mathbf{N}$ & Median (q1-q3) & $\mathbf{N}$ & Median (q1-q3) & $\mathbf{N}$ & Median (q1-q3) & $\mathbf{N}$ & Median (q1-q3) & \\
\hline $\begin{array}{l}\text { Number of new full } \\
\text { treatment cases started in } \\
2004\end{array}$ & 136 & $202(150-300)$ & 34 & $212.5(150-350)$ & 28 & $205(150-300)$ & 74 & $202(150-300)$ & 0.95 \\
\hline $\begin{array}{c}\text { Method of payment } \\
\% \text { Private Insurance } \\
\% \text { Medicaid } \\
\% \text { No Insurance } \\
\% \text { Other Funding }\end{array}$ & $\begin{array}{l}160 \\
130 \\
161 \\
81\end{array}$ & $\begin{array}{c}50(38.5-65) \\
0(0-5) \\
50(30-60) \\
0(0-1) \\
\end{array}$ & $\begin{array}{l}38 \\
38 \\
38 \\
19\end{array}$ & $\begin{array}{c}44(30-62) \\
6(3-10) \\
45.5(27-55) \\
0(0-2)\end{array}$ & $\begin{array}{l}33 \\
23 \\
33 \\
12\end{array}$ & $\begin{array}{c}55(40-70) \\
0(0-2) \\
42(30-59) \\
0(0-0)\end{array}$ & $\begin{array}{l}89 \\
69 \\
90 \\
50\end{array}$ & $\begin{array}{c}50(40-65) \\
0(0-0) \\
50(30-60) \\
0(0-2)\end{array}$ & $\begin{array}{l}0.13 \\
\sim \sim \sim \\
0.39\end{array}$ \\
\hline $\begin{array}{l}\text { Percentage of referred } \\
\text { patients with Medicaid }\end{array}$ & 165 & $2.0(0-5)$ & 40 & $10.0(3.5-20)$ & 32 & $1.0(0-5)$ & 93 & $0.0(0-2)$ & $<.0001$ \\
\hline $\begin{array}{l}\text { Percentage of new cases } \\
\text { with no fee }\end{array}$ & 83 & $1.0(1-2)$ & 20 & $1.0(1-2)$ & 15 & $1.0(0-2)$ & 48 & $1.0(1-2)$ & 0.29 \\
\hline $\begin{array}{l}\text { Percentage of new cases } \\
\text { with discounted fee }\end{array}$ & 102 & $3.0(2-5)$ & 28 & $3.0(2-10)$ & 22 & $2.0(1-10)$ & 52 & $2.5(1-5)$ & 0.61 \\
\hline $\begin{array}{l}\text { Number of Medicaid } \\
\text { inquiries per month }\end{array}$ & 154 & $5(2-10)$ & 37 & $10(3-20)$ & 30 & $10(3-20)$ & 87 & $4(1-10)$ & 0.001 \\
\hline & & $\overline{~ N ~(\%) ~}$ & & "N (\%) & & N N (\%) & & N N (\%) & \\
\hline $\begin{array}{c}\text { Practice Arrangement } \\
\text { Solo } \\
\text { Non-solo }\end{array}$ & & $\begin{array}{l}121(73.33) \\
44(26.67)\end{array}$ & & $\begin{array}{l}30(75.00) \\
10(25.00)\end{array}$ & & $\begin{array}{l}25(78.13) \\
7(21.88)\end{array}$ & & $\begin{array}{l}66(70.97) \\
27(29.03)\end{array}$ & 0.60 \\
\hline $\begin{array}{c}\text { Busyness } \\
\text { Too Busy } \\
\text { Comfortable load } \\
\text { Not busy enough }\end{array}$ & & $\begin{array}{l}21(12.88) \\
98(60.12) \\
44(26.99)\end{array}$ & & $\begin{array}{l}8(20.51) \\
20(51.28) \\
11(28.21)\end{array}$ & & $\begin{array}{c}3(9.38) \\
20(62.50) \\
9(28.13)\end{array}$ & & $\begin{array}{l}10(10.87) \\
58(63.04) \\
24(26.09)\end{array}$ & 0.60 \\
\hline $\begin{array}{l}\text { Average Fee } \\
\$ 5000 \text { or less } \\
>\$ 5000\end{array}$ & & $\begin{array}{l}101(61.59) \\
63(38.41)\end{array}$ & & $\begin{array}{l}28(70.00) \\
12(30.00)\end{array}$ & & $\begin{array}{l}22(68.75) \\
10(31.25)\end{array}$ & & $\begin{array}{l}51(55.43) \\
41(44.57)\end{array}$ & 0.09 \\
\hline $\begin{array}{l}\text { Quoted no fee or reduced } \\
\text { fee? } \\
\qquad \begin{array}{l}\text { No } \\
\text { Yes }\end{array}\end{array}$ & & $\begin{array}{l}56(34.78) \\
105(65.22)\end{array}$ & & $\begin{array}{l}10(25.64) \\
29(74.36)\end{array}$ & & $\begin{array}{l}10(31.25) \\
22(68.75)\end{array}$ & & $\begin{array}{l}36(40.00) \\
54(60.00)\end{array}$ & 0.12 \\
\hline
\end{tabular}


Only forty practitioners $(24.1 \%)$ reported that they currently accept new Medicaid patients. Of these, $83 \%(n=33)$ do not accept all new Medicaid patients. The primary restriction was acceptance only of referred new Medicaid patients. Sixteen providers (40\%) indicated that they would accept medically compromised new Medicaid patients. For current Medicaid providers, the median of the patient population covered by Medicaid was 6\%. Only $15 \%(n=6)$ reported that Medicaid patients make up more than $20 \%$ of their patients. Five $(12.5 \%)$ reported a net profit from these cases. Fifteen $(37.5 \%)$ reported breaking even, and twenty $(50.0 \%)$ reported a net loss. Using data obtained from the North Carolina State Dental Board of Licensing Section of the Health Professions Data System (HPDS), Medicaid providers were located in 25 out of 100 counties in North Carolina (Figure 1). Based on the population density and median family income for each county ${ }^{16}$, there is no apparent trend that Medicaid providers are located in counties with lower population densities or lower median family incomes (Table III).

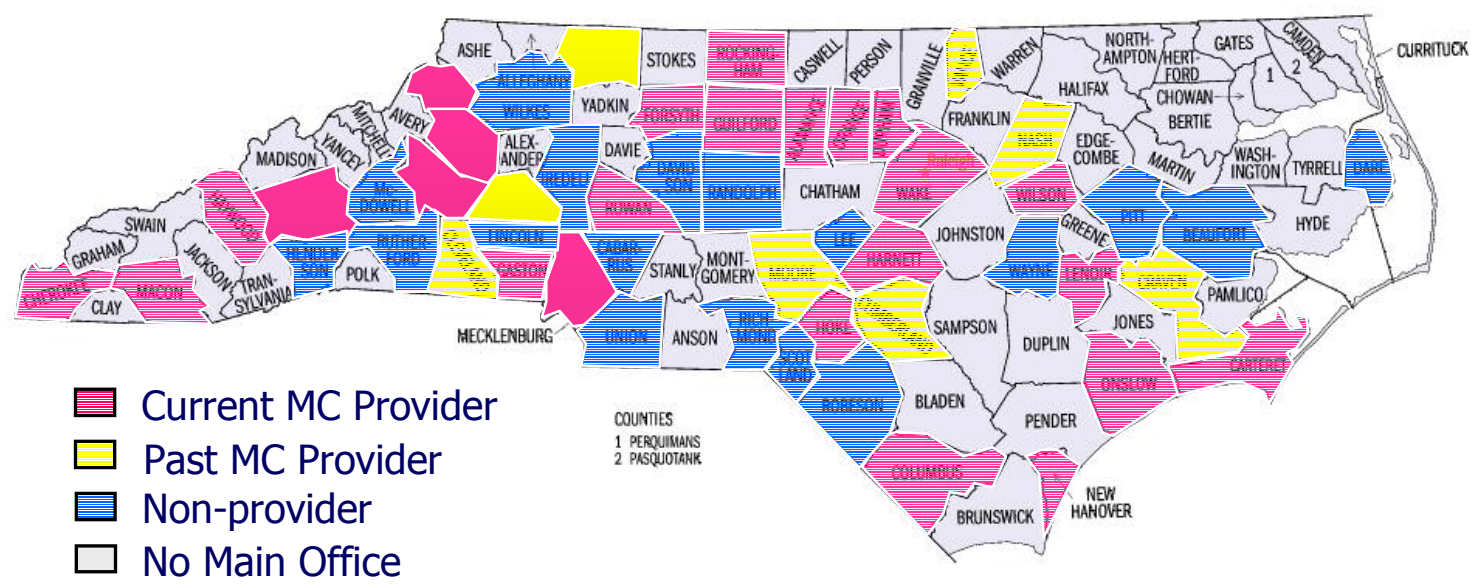

Fig 1. County affiliations for respondents. "No Main Office" indicates those counties lacking an orthodontist with a main office located within its borders, as reported by the North Carolina Health Professions Data System. 
TABLE III: NUMBER OF CURRENT AND PAST MEDICAID PROVIDERS BY COUNTY

\begin{tabular}{|c|c|c|c|c|}
\hline County & $\begin{array}{l}\text { Population } \\
\text { Density* } \\
\text { (per km²) }\end{array}$ & $\begin{array}{l}\text { Median Family } \\
\text { Income* }^{*} \\
\text { (dollars) }\end{array}$ & $\begin{array}{c}\text { Number of } \\
\text { Current } \\
\text { Medicaid } \\
\text { Providers } \\
(\mathrm{N}=40)\end{array}$ & $\begin{array}{c}\text { Number of } \\
\text { Past Medicaid } \\
\text { Providers } \\
(\mathrm{N}=33)\end{array}$ \\
\hline Alamance & 117 & 46,479 & 3 & 0 \\
\hline Buncombe & 121 & 45,011 & 2 & 2 \\
\hline Burke & 68 & 42,114 & 3 & 0 \\
\hline Caldwell & 63 & 41,665 & 1 & 0 \\
\hline Carteret & 44 & 45,499 & 2 & 0 \\
\hline Catawba & 137 & 47,474 & 0 & 1 \\
\hline Cherokee & 21 & 33,768 & 1 & 0 \\
\hline Columbus & 80 & 33,849 & 1 & 0 \\
\hline Craven & 50 & 42,574 & 0 & 2 \\
\hline Cumberland & 50 & 41,459 & 0 & 2 \\
\hline Durham & 297 & 53,223 & 2 & 2 \\
\hline Forsyth & 289 & 52,032 & 2 & 1 \\
\hline Gaston & 206 & 46,271 & 1 & 1 \\
\hline Guilford & 250 & 52,638 & 3 & 3 \\
\hline Harnett & 59 & 41,176 & 1 & 0 \\
\hline Haywood & 38 & 40,438 & 1 & 0 \\
\hline Hoke & 33 & 36,110 & 1 & 0 \\
\hline Lenoir & 58 & 38,815 & 1 & 0 \\
\hline Macon & 22 & 37,381 & 1 & 0 \\
\hline Mecklenburg & 510 & 60,608 & 4 & 4 \\
\hline Moore & 41 & 48,492 & 0 & 1 \\
\hline Nash & 62 & 44,769 & 0 & 1 \\
\hline New Hanover & 311 & 50,861 & 1 & 2 \\
\hline Onslow & 76 & 36,692 & 2 & 1 \\
\hline Orange & 114 & 59,874 & 2 & 0 \\
\hline Rockingham & 63 & 40,821 & 1 & 0 \\
\hline Rowan & 98 & 44,242 & 1 & 0 \\
\hline Rutherford & 43 & 37,787 & 0 & 1 \\
\hline Surry & 51 & 38,902 & 0 & 1 \\
\hline Vance & 65 & 36,389 & 0 & 1 \\
\hline Wake & 291 & 67,149 & 1 & 6 \\
\hline Watauga & 53 & 45,508 & 1 & 0 \\
\hline Wilson & 77 & 41,551 & 1 & 1 \\
\hline
\end{tabular}


One-hundred twenty-six (75.9\%) of the 166 respondents did not currently accept new Medicaid patients. Thirty-three $(26.2 \%)$ of the nonparticipating orthodontists reported accepting Medicaid in the past but not currently: $42.4 \%(n=14)$ stopped accepting Medicaid patients in the last 6 years (2000 or later) and 45.5\% ( $\mathrm{n}=15)$ stopped between 1990 and 1999. The county affiliation of respondents who previously accepted Medicaid patients is illustrated in Figure 1. Ninety-three of the 126 nonparticipating orthodontists (73.8\%) reported never accepting Medicaid.

The age, race, gender, and number of years in practice did not differ statistically among the three groups (current Medicaid providers, non-providers who accepted Medicaid at one time, and non-providers who have never accepted Medicaid) (Table I). Nor did the three groups differ in the number of new full treatment cases started in 2004, percentage of cases that had private insurance, percentage of cases that had no insurance coverage, percentage of cases quoted no fee or a reduced fee because the patient could not afford treatment, practice arrangement (solo versus non-solo), how busy the practitioner perceived the practice to be, or the proportion of practitioners with an average fee greater than $\$ 5000$ (Table II). Medicaid providers did have a significantly higher percentage of referred patients with Medicaid than both groups of non-providers $(\mathrm{p}<.0001)$. Current Medicaid providers, along with those who used to accept Medicaid in the past, also had a higher number of Medicaid inquiries in a typical month than non-providers who have never accepted Medicaid $(\mathrm{p}=.001)$.

A large number of non-providers who have never accepted Medicaid responded with "don't know" to questions regarding reasons why orthodontists may limit the number of Medicaid patients they treat (Table IV). Thus, for the items related to barriers to participation in Medicaid, these respondents were excluded from the analyses. 
All three groups perceived low fee reimbursement to be a major problem with the Medicaid program (Table IV). This was the only issue where the opinions of the three groups did not differ significantly. For the remaining issues (Table IV), current Medicaid providers, in general, perceived the issues to be no problem or a minor problem while non-providers (past and never) tended to report the issues to be minor or major problems. Interestingly, those who never accepted Medicaid and expressed an opinion were more likely to perceive the issues as major problems. 


\begin{tabular}{|c|c|c|c|c|c|c|}
\hline \multicolumn{2}{|c|}{$\begin{array}{l}C=\text { Current Medicaid Provider } \\
A=\text { Accepted Medicaid at one time } \\
N=\text { Never accepted Medicaid }\end{array}$} & \multirow{2}{*}{$\begin{array}{c}\begin{array}{c}\text { Don't } \\
\text { Know* } \\
\text { (N) }\end{array} \\
(0) \\
(0) \\
(14)\end{array}$} & \multirow{2}{*}{$\begin{array}{c}\begin{array}{c}\text { Not a } \\
\text { Problem } \\
\text { N (\%) }\end{array} \\
0(0) \\
0(0) \\
3(3.90)\end{array}$} & \multirow{2}{*}{$\begin{array}{c}\begin{array}{c}\text { Minor } \\
\text { Problem } \\
\text { N (\%) }\end{array} \\
8(20.00) \\
7(21.21) \\
9(11.69)\end{array}$} & \multirow{2}{*}{$\begin{array}{c}\begin{array}{c}\text { Major } \\
\text { Problem } \\
\text { N (\%) }\end{array} \\
32(80.00) \\
26(78.79) \\
65(84.42)\end{array}$} & \multirow{2}{*}{$\begin{array}{c}\text { p value } \\
1.0\end{array}$} \\
\hline $\begin{array}{l}\text { Fee reimbursement } \\
\text { too low }(N=164)\end{array}$ & $\begin{array}{l}\mathbf{C} \\
\mathrm{A} \\
\mathrm{N}\end{array}$ & & & & & \\
\hline $\begin{array}{l}\text { Difficulty collecting } \\
\text { from Medicaid } \\
(\mathrm{N}=161)\end{array}$ & $\begin{array}{l}\text { C } \\
\text { A } \\
\text { N }\end{array}$ & $\begin{array}{l}(0) \\
(3) \\
(57)\end{array}$ & $\begin{array}{l}14(35.00) \\
7(24.14) \\
2(6.25)\end{array}$ & $\begin{array}{l}17(42.50) \\
12(41.38) \\
11(34.38)\end{array}$ & $\begin{array}{l}9(22.50) \\
10(34.48) \\
19(59.38)\end{array}$ & 0.0003 \\
\hline $\begin{array}{l}\text { Loss of coverage } \\
\text { during treatment } \\
(\mathrm{N}=159)\end{array}$ & $\begin{array}{l}\mathbf{C} \\
\mathbf{A} \\
\mathrm{N}\end{array}$ & $\begin{array}{l}(4) \\
(4) \\
(51)\end{array}$ & $\begin{array}{c}14(40.00) \\
11(39.29) \\
3(8.11)\end{array}$ & $\begin{array}{l}14(40.00) \\
8(28.57) \\
5(13.51)\end{array}$ & $\begin{array}{c}7(20.00) \\
9(32.14) \\
29(78.38)\end{array}$ & $<.0001$ \\
\hline $\begin{array}{l}\text { Need for prior } \\
\text { authorization }(\mathrm{N}=161)\end{array}$ & $\begin{array}{l}\mathbf{C} \\
\mathbf{A} \\
\mathrm{N}\end{array}$ & $\begin{array}{l}(0) \\
(0) \\
(24)\end{array}$ & $\begin{array}{l}10(25.00) \\
5(15.15) \\
4(6.25)\end{array}$ & $\begin{array}{l}19(47.50) \\
11(33.33) \\
24(37.50)\end{array}$ & $\begin{array}{l}11(27.50) \\
17(51.52) \\
36(56.25)\end{array}$ & 0.001 \\
\hline $\begin{array}{l}\text { Getting billing } \\
\text { questions answered } \\
(\mathrm{N}=161)\end{array}$ & $\begin{array}{l}\text { C } \\
\text { A } \\
\text { N }\end{array}$ & $\begin{array}{l}(2) \\
(5) \\
(62)\end{array}$ & $\begin{array}{l}9(23.68) \\
6(21.43) \\
0(0)\end{array}$ & $\begin{array}{l}21(55.26) \\
12(42.86) \\
7(26.92)\end{array}$ & $\begin{array}{l}8(21.05) \\
10(35.71) \\
19(73.08)\end{array}$ & $<.0001$ \\
\hline $\begin{array}{l}\text { Delays in receiving } \\
\text { payment }(\mathrm{N}=158)\end{array}$ & $\begin{array}{l}\mathbf{C} \\
\mathbf{A} \\
\mathrm{N}\end{array}$ & $\begin{array}{l}(1) \\
(5) \\
(62)\end{array}$ & $\begin{array}{c}10(27.03) \\
7(25.00) \\
1(4.00)\end{array}$ & $\begin{array}{l}20(54.05) \\
13(46.43) \\
6(24.00)\end{array}$ & $\begin{array}{c}7(18.92) \\
8(28.57) \\
18(72.00)\end{array}$ & 0.0001 \\
\hline $\begin{array}{l}\text { Unruly/uncooperative } \\
\text { behavior }(\mathrm{N}=160)\end{array}$ & $\begin{array}{l}\mathbf{C} \\
\mathbf{A} \\
\mathrm{N}\end{array}$ & $\begin{array}{l}(0) \\
(1) \\
(34)\end{array}$ & $\begin{array}{l}11(28.95) \\
4(12.5) \\
2(3.64)\end{array}$ & $\begin{array}{l}17(44.74) \\
14(43.75) \\
17(30.91)\end{array}$ & $\begin{array}{l}10(26.32) \\
14(43.75) \\
36(65.45)\end{array}$ & $<.0001$ \\
\hline $\begin{array}{l}\text { Patient may fail to } \\
\text { show for appts } \\
\text { ( } N=161)\end{array}$ & $\begin{array}{l}\mathbf{C} \\
\mathrm{A} \\
\mathrm{N}\end{array}$ & $\begin{array}{l}(0) \\
(1) \\
(21)\end{array}$ & $\begin{array}{c}3(7.69) \\
0(0) \\
2(2.94)\end{array}$ & $\begin{array}{l}19(48.72) \\
6(18.75) \\
6(8.82)\end{array}$ & $\begin{array}{l}17(43.59) \\
26(81.25) \\
60(88.24)\end{array}$ & $<.0001$ \\
\hline $\begin{array}{l}\text { Patients are often } \\
\text { late }(\mathrm{N}=161)\end{array}$ & $\begin{array}{l}\mathbf{C} \\
\mathbf{A} \\
\mathrm{N}\end{array}$ & $\begin{array}{l}(0) \\
(1) \\
(23)\end{array}$ & $\begin{array}{l}7(17.95) \\
1(3.13) \\
1(1.52)\end{array}$ & $\begin{array}{l}20(51.28) \\
9(28.13) \\
8(12.12)\end{array}$ & $\begin{array}{l}12(30.77) \\
22(68.75) \\
57(86.36)\end{array}$ & $<.0001$ \\
\hline $\begin{array}{l}\text { Patients cancel at the } \\
\text { last minute }(N=161)\end{array}$ & $\begin{array}{l}\mathbf{C} \\
\mathbf{A} \\
\mathbf{N}\end{array}$ & $\begin{array}{l}(0) \\
(2) \\
(29)\end{array}$ & $\begin{array}{l}8(20.51) \\
3(9.68) \\
1(1.67)\end{array}$ & $\begin{array}{l}22(56.41) \\
14(45.16) \\
11(18.33)\end{array}$ & $\begin{array}{c}9(23.08) \\
14(45.16) \\
48(80.00)\end{array}$ & $<.0001$ \\
\hline
\end{tabular}


Analyses were conducted to compare current Medicaid providers with those who used to accept Medicaid in the past to see what may have led the latter group to stop participating in the Medicaid program. These two groups did not differ in any practitioner characteristic ( $\mathrm{p}$ values $>0.59$ ). The only practice characteristic (Table II) that differed between the two groups was the average percentage of referred patients covered by Medicaid $(p<.0001)$. The two groups did not differ in their opinions of the logistics of the Medicaid program $(p>0.06)$, but did differ in their perceptions of Medicaid patients. A larger proportion of past Medicaid providers perceived patient behaviors to be a problem than did current providers: uncooperative behavior $(\mathrm{p}=.07)$; last-minute cancellations $(\mathrm{p}=0.05)$ broken appointments $(p=0.001)$; tardiness for appointments $(p=0.001)$.

\section{DISCUSSION}

\section{Level of practitioner participation}

The North Carolina Department of Health and Human Services (DHHS) reported that sixty-one orthodontists participated in the Medicaid program from July 1st, 2002 to June $30^{\text {th }}$, 2003. However, most of them treated only a small number of Medicaid patients. The ten practitioners who treated 50 or more Medicaid cases during that year accounted for $83.6 \%$ of the total number of cases banded. In an environment of growing numbers of Medicaid eligible individuals, barriers to care prevent those of low socioeconomic status from

accessing orthodontic treatment and realizing the psychosocial and oral health advantages ${ }^{17,18}$ from an improved appearance and oral function. In 2004, 5670 orthodontic cases were submitted for prior authorization, with 64.9\% $(\mathrm{n}=3680)$ approved. In 2005, 7924 cases (a $40 \%$ increase from the last year) were submitted and $63.7 \%(\mathrm{n}=5044)$ were approved. With less than $25 \%$ of practicing orthodontists currently accepting new Medicaid patients, 
compounded by low percentages of patients in their practices with Medicaid coverage (median of 6\%), and only 6 current providers reporting that Medicaid patients make up more than $20 \%$ of their patients, our study confirmed that low levels of participation by orthodontists and small percentage of Medicaid cases in a practice severely limit meeting the goals of the Early and Periodic Screening, Diagnosis, and Treatment (EPSDT) program.

Low levels of practitioner participation have always plagued the success of the Medicaid program. This statement is true not only for orthodontics, but for other fields of dentistry and medicine nationwide. Since the 1970s, physician participation in Medicaid programs has been declining nationally. ${ }^{19,20}$ The high proportion of practitioners refusing to participate in the program is a major problem since it prevents Medicaid patients from accessing health care. Reasons for this decline include inadequate reimbursement, excessive paperwork/administrative burdens, payment delays, litigation concerns, and patient abuses of the program. ${ }^{20-22}$ The blame for low participation in dentistry has also been placed on similar issues. $^{4,5,7-11}$

\section{Practitioner and practice characteristics}

Practitioner and practice characteristics do not appear to influence whether an orthodontist in North Carolina participates in the Medicaid program. This is unlike the findings from other areas of medicine and dentistry ${ }^{4,5,11,23}$ which postulate that age, number of years in practice, perceptions of how busy the practice is, practice arrangement, and average fees can affect a practitioner's decision to accept Medicaid. The effect of practice location, which has been shown to possibly influence Medicaid participation levels ${ }^{5,14,23}$, was not evaluated in depth in this study. However, the Medicaid providers who responded to the survey are located in only 25 of the 100 counties in North Carolina, with the northeastern 
part of the state having the least access to an orthodontist who accepts Medicaid (Figure 1). With the withdrawal of past providers from the Medicaid program, 8 more counties may not have an orthodontist who accepts Medicaid. Interestingly, the county with the highest number of current Medicaid providers has the highest population density and the $2^{\text {nd }}$ highest median family income of all of the NC counties (Table III). Thus, there is likely more to the decision to participate in the Medicaid program than practice location. Medicaid providers had a larger average percentage of referred patients on Medicaid $(\mathrm{p}<.0001)$ and a higher number of Medicaid inquiries in a typical month $(\mathrm{p}=.001)$ suggesting that either these practitioners are located where Medicaid-eligible individuals live, or Medicaid patients are being referred to orthodontists who are known to accept them.

Orthodontists in Washington State who accepted Medicaid provided more discounted fees, received more inquiries from Medicaid patients, and were more likely to feel overworked. ${ }^{14}$ In NC, however, the three groups of providers did not differ significantly in the average percentage of cases for whom no fee or discounted fee was quoted. One possible explanation is that non-providers may be giving back to the community by quoting no fee or discounted fees rather than dealing with the "hassle" of the Medicaid system ${ }^{7}$. A few respondents who reported not accepting Medicaid payment did report a small percentage of their patient population being on Medicaid. Those who previously accepted Medicaid may have Medicaid patients that are not yet finished with treatment; they may not officially participate in the Medicaid program but may accept a certain number of referrals; or they may accept certain Medicaid patients on a case-by-case basis. Even a few orthodontists who reported never having accepted Medicaid reported that a very small percentage of their total 
patient population is on Medicaid. These practitioners also may accept a few cases from special referrals or may accept certain patients on an individual basis.

\section{Perceptions of the Medicaid program and patients}

If practitioner and practice characteristics are not related to participation by $\mathrm{NC}$ orthodontists in the Medicaid program, what could influence an orthodontist's decision to participate? All three groups felt that the low fee reimbursement was a major problem with the Medicaid program (Table IV). This finding is congruent with previous studies., ${ }^{4,5-}$ 11,14,20,22 With reimbursement rates of only about 55 to 65 percent of the customary fee, and coverage limited to severe "handicapping" malocclusions that would likely require more resources, it is not surprising that this may have an effect on the level of participation by orthodontists. Even so, low fee reimbursement and minimal opportunity for profiting financially did not appear to deter those who currently accept Medicaid from treating these patients. This supports the theory that factors affecting providers' participation in the Medicaid program are more complex than dissatisfaction with low reimbursement fees. ${ }^{9,11,23,24}$

Many of the orthodontists who have never accepted Medicaid responded with "don't know" to the questions in the perceived problems section. Except for the need for prior authorization (Table IV), the majority (57 to 70\%) responded with "don't know" to the issues related to the logistics of the Medicaid system. The lack of opinion regarding the Medicaid system may reflect a lack of knowledge about actual procedures and implementation of Medicaid coverage. Margolis et $\mathrm{al}^{23}$ found that pediatricians who knew less about the Medicaid program restricted access more often. Educating practitioners regarding the 
logistics of the Medicaid program may dispel some of the perceptions they may have regarding the system itself.

Substantially fewer (24 to 38\%) of those who have never accepted Medicaid responded with "don't know" to the patient-related issues. Of those who gave an opinion on the perceived barriers, the majority felt that all of the issues, both logistic and patient related, represented major problems (Table IV). In fact, over $80 \%$ cited the issues related to disruption of practice efficiency (no show/cancellation/tardiness) as major problems. Perhaps these preconceived perceptions could be altered by incorporating Medicaid patients into residency clinics to allow residents hands-on experience with the logistics of the system and give them a more realistic view of the Medicaid program and patients. Residency training programs can also foster a higher level of altruism and sense of social responsibility through educating about public health principles. Extramural rotations would also encourage residents to be more socially and culturally aware. In addition, the local dental community and the influence of peers may play an important role in decreasing barriers to access.

Because Medicaid approves a case based on whether it is a "handicapping occlusion," Medicaid coverage is usually limited to patients with severe malocclusions who require complex and costly treatment approaches. King et $\mathrm{al}^{14}$ and Mirabelli et $\mathrm{al}^{25}$ suggest that a program of interceptive orthodontics would provide substantial benefit at a reduced cost per patient and may increase participation and access to orthodontic services under Medicaid. No data is currently available on the view of orthodontists in North Carolina on the types of problems and staging of treatment offered under Medicaid.

Providers who have stopped accepting Medicaid did not significantly differ from current providers in their perception of the problem level associated with issues related to the 
Medicaid program but did differ in their perception of the problem level associated with patient-related behaviors. Past providers felt that broken appointments ( $44 \%$ current versus $81 \%$ past) and tardiness ( $31 \%$ versus $69 \%$ ) were major problems, which may have influenced their decision to discontinue accepting new Medicaid patients. Mirabelli et $\mathrm{al}^{25}$ reported that, although Medicaid patients had more broken appointments and poorer oral hygiene, compliance did not appear to affect the final treatment result. However, practitioners in North Carolina may have withdrawn from the Medicaid program due to disruption of practice efficiency.

\section{CONCLUSIONS}

This investigation examined participation and perceptions of the Medicaid program among practicing orthodontists in North Carolina. Therefore broad generalization of the findings should be made with caution; however, under the conditions of this study we conclude the following:

1. The effective response rate was 82 percent (166/203). Only forty North Carolina orthodontists in our sample currently accept new Medicaid patients. Thirty-three of the remaining orthodontists do not currently accept new Medicaid patients but did at some point in the past. Ninety-three orthodontists reported never participating in the Medicaid program.

2. Current Medicaid providers, non-providers who used to accept Medicaid in the past, and non-providers who never accepted Medicaid did not differ with respect to age, gender, number of years in practice, number of new full treatment cases started in 2004, percentage of cases that had private insurance, percentage of cases that had no insurance coverage, percentage of cases quoted no fee or a 
reduced fee because the patient could not afford treatment, practice arrangement (solo versus non-solo), busyness, or average fee. The only practice characteristics that differed significantly among the three groups were the percentage of referred patients that have Medicaid and the number of Medicaid inquiries per month.

3. All three groups perceived low fee reimbursement to be a major problem with the Medicaid program.

4. Non-providers who never participated in the Medicaid program and who gave an opinion perceived each of the barriers to accepting Medicaid as major problems.

5. Orthodontists who have never accepted Medicaid responded with "don't know" for many of the barriers related to the logistics of the Medicaid program. This finding implies that non-providers need to be educated about the Medicaid system. In reference to Medicaid patients, however, these practitioners felt that unruly/uncooperative behavior, broken appointments, patients being late, and lastminute cancellations are major barriers to accepting Medicaid.

6. Problems with patient-related issues (broken appointments and late arrivals for appointments) may have led some orthodontists to withdraw from the Medicaid program. 


\section{REFERENCES}

1. GAO (2000) Oral Health: Dental Disease is a Chronic Problem Among Low-Income Populations. Washington, DC: General Accounting Office, April 2000.

2. Salzmann JA. Orthodontics under Medicare and Medicaid. Am J Orthod. 1966 Dec;52(12):922-6.

3. Parker WS. Government and orthodontics in California in 1994. Am J Orthod Dentofacial Orthop. 1995 Mar;107(3):22A-3A.

4. Venezie RD, Vann WF,Jr. Pediatric dentists' participation in the North Carolina Medicaid program. Pediatr Dent. 1993 May-Jun;15(3):175-81.

5. Lang WP, Weintraub JA. Comparison of Medicaid and non-Medicaid dental providers. J Public Health Dent. 1986 Fall;46(4):207-11.

6. Mofidi M, Rozier RG, King RS. Problems with access to dental care for Medicaidinsured children: what caregivers think. Am J Public Health. 2002 Jan;92(1):53-8.

7. Damiano PC, Brown ER, Johnson JD, Scheetz JP. Factors affecting dentist participation in a state Medicaid program. J Dent Educ. 1990 Nov;54(11):638-43.

8. Capilouto E. The dentist's role in access to dental care by Medicaid recipients. J Dent Educ. 1988 Nov;52(11):647-52.

9. Milgrom P, Riedy C. Survey of Medicaid child dental services in Washington state: preparation for a marketing program. J Am Dent Assoc. 1998 Jun;129(6):753-63.

10. Nainar SM, Tinanoff N. Effect of Medicaid reimbursement rates on children's access to dental care. Pediatr Dent. 1997 Jul-Aug;19(5):315-6.

11. Shulman JD, Ezemobi EO, Sutherland JN, Barsley R. Louisiana dentists' attitudes toward the dental Medicaid program. Pediatr Dent. 2001 Sep-Oct;23(5):395-400.

12. Kelly JE, Harvey CR. An assessment of the occlusion of the teeth of youths 12-17 years. Vital Health Stat 11. 1977 Feb;(162)(162):1-65.

13. Kelly JE, Sanchez M, Van Kirk LE. An assessment of the occlusion of the teeth of children 6-11 years. DHEW Publication No. (HRA) 74-1617. Washington, 1973, National Center for Health Statistics.

14. King GJ, Hall CV, Milgrom P, Grembowski DE. Early orthodontic treatment as a means to increase access for children enrolled in medicaid in Washington state. J Am Dent Assoc. 2006 Jan;137(1):86-94.

15. Salant P, Dillman DA. How to conduct your own survey. New York: Wiley; 1994. 
16. U.S. Census Bureau [homepage on the Internet]. [Cited 2006 Feb 1]. Available from: http://www.census.gov/main/www.cen2000.html.

17. Proffit WR. Contemporary orthodontics. $3^{\text {rd }}$ ed. St. Louis: Mosby; 2000.

18. McLain JB, Proffit WR. Oral health status in the United States: prevalence of malocclusion. J Dent Educ. 1985 Jun;49(6):386-97.

19. Mitchell JB. Physician participation in Medicaid revisited. Med Care. 1991 Jul;29(7):645-53.

20. Silverstein G. Physicians' perceptions of commercial and Medicaid managed care plans: a comparison. J Health Polit Policy Law. 1997 Feb;22(1):5-21.

21. Gold M, Kuo S, Taylor EF. Translating research to action: improving physician access in public insurance. J Ambul Care Manage. 2006 Jan-Mar;29(1):36-50.

22. Garner DD, Liao WC, Sharpe TR. Factors affecting physician participation in a state Medicaid program. Med Care. 1979 Jan;17(1):43-58.

23. Margolis PA, Cook RL, Earp JA, Lannon CM, Keyes LL, Klein JD. Factors associated with pediatricians' participation in Medicaid in North Carolina. JAMA. 1992 Apr 8;267(14):1942-6.

24. Lam M, Riedy CA, Milgrom P. Improving access for Medicaid-insured children: focus on front-office personnel. J Am Dent Assoc. 1999 Mar;130(3):365-73.

25. Mirabelli JT, Huang GJ, Siu CH, King GJ, Omnell L. The effectiveness of phase I orthodontic treatment in a Medicaid population. Am J Orthod Dentofacial Orthop. 2005 May;127(5):592-8. 